Crawford, Kathleen, Heatley, N. G., Boyd, Pamela F., Hale, C. W., Kelly, B. K., Miller, G. A. \& Smith, Nancy (1952). J. gen. Microbiol. 6, 47-59.

\title{
Antibiotic Production by a Species of Cephalosporium
}

\author{
By KATHLEEN CRAWFORD AND N. G. HEATLEY \\ Sir William Dunn School of Pathology, University of Oxford \\ and PAMELA F. BOYD, C. W. HALE, B. K. KELLY, G. A. MILLER \\ AND NANCY SMITH
}

Medical Research Council Antibiotics Research Station, Clevedon, Somerset

SUMMARY: The antibacterial activity of a strain of a Cephalosporium sp. was found to be due to a number of antibiotics. One group of these, named Cephalosporins $P$, is soluble in organic solvents and active only against Gram-positive bacteria.

The $\mathbf{P}$ antibiotic(s) is produced in good yield in deep culture in a medium comprising corn steep liquor and glucose at an initial $\mathrm{pH}$ of $6 \cdot 3$. A high aeration rate assisted by adequate stirring is essential. Submerged cultures $72 \mathrm{hr}$. old form convenient inocula. Under optimum conditions with $2 \%(\mathrm{v} / \mathrm{v})$ of such an inoculum the maximum titre is reached after $\mathbf{4 7 - 5 0 ~ h r}$. at $24^{\circ}$, and thereafter falls.

The production of a diffusible antibacterial substance by a species of Cephalosporium was reported by Brotzu (1948) in an apparently little-known paper which was brought to the notice of Sir Howard Florey by Dr C. O. S. Blyth Brooke. Prof. Brotzu kindly provided a culture of the organism, which was one of a number showing antibacterial action which he has isolated from the sea near a sewage outfall off Sardinia. This locality had been chosen with the expectation that antagonistic organisms would be plentiful there in view of the 'self-purification' known to occur in sewage. The organism, C. acremonium or a closely related species, grew at room temperature on a number of complex solid and liquid media preferably containing added carbohydrate (e.g. glucose, lactose or starch) and a 'titre' of 1/10 to 1/15 (test organism not specified) was reached in 4-8 days. The addition of various amino-acids, extracts of yeast, corn germ, peas, etc., had little effect on the titre which was, however, about six times greater from one daughter strain selected from hundreds tested. Streaking tests on solid media showed marked inhibition of Salmonella typhi, S. paratyphi B, Shigella shiga-kruze, Vibrio cholerae, Staphylococcus aureus, Brucella melitensis, Bacillus anthracis and Pasteurella pestis. There was no action against Pseudomonas aerogenes. Brotzu found that the active substance was rather unstable and various methods of extraction and purification were tried with little success. An active extract could be made by concentrating the filtered broth (which was usually yellow) to $1 / 10$ its volume in a current of air at $25^{\circ}$, adding 1.5 vol. of $98 \%$ ethanol, removing the precipitate by filtration through cotton-wool, and concentrating the ethanol extract at $37-40^{\circ}$. In an improved process (Brotzu, personal communication to Sir Howard Florey) the ethanolic extract obtained as above was shaken with about 3 vol. of acetone. The precipitate thereby formed was dissolved in 
a little water, mixed with 5 vol. of $96 \%$ ethanol, then, after discarding the precipitate, with $30 \mathrm{vol}$. of acetone. The precipitate, dissolved in a small volume of water, was treated with charcoal (Merck, $1 \mathrm{~g} . / 10 \mathrm{ml}$.) for $1 \mathrm{hr}$. After centrifuging, the supernatant, which was almost colourless, contained a good deal of activity. Both the crude culture-fluid and extracts of it were tested clinically. Good results were claimed from local treatment of pyogenic infections and from the general treatment of typhoid and paratyphoid fevers, and brucellosis.

The work reported here falls into two parts: preliminary observations made at Oxford, and further work relating to large-scale production done at Clevedon. It was established that the fungus could form one or more sub. stances active mainly against Gram-positive organisms, and one substance also active against Gram-negative species. It is probable that the latter was responsible for most of Brotzu's observations. The preliminary work at Oxford reported here must have been mainly concerned with the Grampositive inhibitory substance(s). The isolation and characterization of the latter are described by Burton \& Abraham (1951), and some bacteriological and in vivo studies of them are reported by Ritchie, Smith, \& Florey (1951).

\section{PRELIMINARY OBSERVATIONS}

Assay. Inhibitory material from cultures of the Cephalospcrium strain diffused readily through agar and was easily assayed by the cylinder-plate method (Heatley, 1944) against either Staph. aureus NCTC 6571 or a laboratory strain of Corynebacterium xerosis. With either organism there was an increment of 3-4 mm. in zone diameter for each doubling of concentration of the inhibitor. A crude active culture-filtrate was tentatively selected as a standard, being assigned a potency of 1 unit/ml.; other fluids and, later, a dry powder, were standardized in terms of it. Though both solid and fluid preparations were liable to lose activity quickly, there was no evidence that any of the standards (kept at $+4^{\circ}$, and, if in powder form, over calcium chloride also) lost appreciable activity. A concentration of 1 unit/ml. gave a zone 17-22 mm. in diameter with either of the above test organisms.

Preparation of inocula. Various solid media, with and without calcium carbonate, were tested for the production of spores by this strain of Cephalosporium. Spores were freely formed after 8 days at $24^{\circ}$ on a medium $(\mathrm{pH} 7 \cdot 4)$ consisting of $1 \%$ Lemco, $1 \%$ peptone and $1 \%$ glucose. Modifications containing less nitrogen, or simple dilutions of beer or corn steep liquor (CSL), also allowed free sporing, although more slowly. The spores were more readily dispersed when glucose was omitted from the Lemco peptone glucose medium. Aerated cultures also formed very satisfactory inocula.

\section{Cultivation experiments}

In static culture. Active material was readily produced in shallow layers ( $1 \mathrm{~cm}$. or less) of Lemco peptone glucose medium. Up to $2 \mathrm{u} . / \mathrm{ml}$. were formed after 10-12 days at $24^{\circ}$, or after 7-10 days at $37^{\circ}$. Up to $5 \mathrm{u} . / \mathrm{ml}$. were obtained 
in the same medium in successive harvests from cellophan sacs (Heatley \& Florey, 1946), but these became fragile and usually broke within 1-3 weeks, as did sacs of collodion.

When the active medium in a shallow static culture was replaced by fresh medium, the latter in turn became active in about the same length of time as required for the first growth. However, it was difficult to remove culture fluid without sucking away large amounts of the slimy tenuous mycelium. Attempts were made to overcome this by growing the fungus on cellophan completely covering the surface of fluid medium in trays, but although good titres were obtained the cellophan became brittle and tore easily. The fungus was also grown on a thin layer of a mixture of nutrient agar and cork powder which, it was hoped, would float when fluid medium was subsequently introduced. Cork fragments were used in a similar way by Gill-Carey (1950). Though promising, this scheme was abandoned when good results were obtained from submerged aerated cultures.

In aerated submerged culture. The organism grew well in aerated submerged culture and antibiotic activity was obtained comparable to that formed in stationary culture provided the rate of aeration was not less than $1 \mathrm{vol}$. air/vol. medium $/ \mathrm{min}$. An improved yield was obtained with a medium consisting of $5 \%(v / v)$ CSL $+4 \%$ glucose. With $2.5 \%(v / v)$ CSL $+2 \%$ glucose the same titre was reached, but rather more rapidly (4-5 days); with a still more dilute medium the titre was lower. Titres were substantially the same from cultures grown at 24, 29, or $37^{\circ}$, and inhibitory material from cultures in Lemco peptone glucose medium had much the same range of antibacterial action as that from the CSL glucose medium.

Examination of related species of Cephalosporium. Miss A. Beverwyck of the Centraalbureau voor Schimmelcultures, Baarn, kindly examined the organism and stated that it most nearly resembled C. acremonium Cda., C. album Preuss, and $C$. Ballaggii Oomen. These however did not produce the yellow colour in the medium characteristic of Brotzu's organism, nor, in tests at Oxford on solid medium, was any antibacterial activity demonstrated.

\section{Physical and chemical properties}

When culture fluid was heated to $100^{\circ}$ for $10 \mathrm{~min}$. at $\mathrm{pH} 2,6 \cdot 5$ and $8 \cdot 8$ the approximate losses of activity were 40,60 , and $65 \%$ respectively. The crude culture fluid did not appreciably lose activity when evaporated to dryness on a heated watch-glass: the active material in such a dried residue was insoluble in hexane, slightly soluble in ether or chloroform, and more soluble in acetone, ethanol, and water.

The active material did not sublime under reduced pressure. It was extracted from a partially purified watery solution into ether at $\mathrm{pH} 2,4 \cdot 8$, or $6 \cdot 5$, but not at pH 9.6. A proportion of the yellow pigment passed into ether at $\mathrm{pH} 2$, but not at the other three $\mathrm{pH}$ values. Thus extraction into ether at $\mathrm{pH} \mathrm{5}$, followed by re-extraction into water at $\mathrm{pH} \mathrm{9.6,} \mathrm{appeared} \mathrm{to} \mathrm{be} \mathrm{a} \mathrm{useful} \mathrm{step}$ in purification.

The antibiotic material was fairly readily adsorbed on Farnell Grade 14 
charcoal at $\mathrm{pH} \mathrm{2,} \mathrm{but} \mathrm{it} \mathrm{seemed} \mathrm{to} \mathrm{be} \mathrm{necessary} \mathrm{to} \mathrm{acidify} \mathrm{the} \mathrm{solution} \mathrm{before}$ adding the charcoal, otherwise the adsorption was less complete. The adsorbed material was not eluted with neutral or alkaline buffer. Activity was not destroyed when the charcoal was dried, and active material could be eluted with acetone or ethanol or, less effectively, with ether. Elution was almost complete after Soxhlet extraction with ether for $\mathbf{2} \mathrm{hr}$., but there was evidence of slow destruction on refluxing an ether solution of the material for several hours. The yield after elution from charcoal was in no case greater than $50 \%$.

Active material was adsorbed from chloroform on to an alumina column and could be eluted from the appropriate zone thereof with ethanol. Small quantities of crystalline material were seen in the residue from one such active fraction, but there was insufficient to ascertain whether the crystals were antibiotic.

\section{EXPERIMENTAL WORK AT CLEVEDON}

In the first fermentations carried out at Clevedon the antibiotic titre against B. subtilis showed abnormal fluctuations throughout the fermentation, and the amount of activity extracted into amyl acetate (Burton \& Abraham, 1952) bore no resemblance to that in the broth; it was also observed that part of the activity was lost under acid conditions. A likely explanation was the production of more than one antibiotic, one at least being insoluble in amyl acetate. The first part of the work reported below describes experiments to determine the number and nature of the inhibitors present in the fermentation broth, and to distinguish between them. A final section then deals with the larger scale production of one group of these inhibitors.

\section{The demonstration and differentiation of various antibiotics in crude Cephalosporium broth}

Behaviour to preparations containing penicillinase. The 'penicillinase preparations' mostly used were prepared from (1) B. subtilis G.B.S.2 (by courtesy of The Distillers Co. (Biochemicals) Ltd.), and (2) B. subtilis NCTC 6346 by the method of Duthie (1944). In general, 1 vol. of the fluid under test was incubated with $0 \cdot 1$ vol. of a suitable dilution of the enzyme preparation in $0.5 \mathrm{M}$ phosphate buffer $\left(\mathrm{pH} \mathrm{7 \cdot 8)}\right.$ at $35^{\circ}$ for $2 \mathrm{hr}$.

It was shown by Burton \& Abraham (1952) that penicillinase prepared from $B$. subtilis NCTC 6346 inactivated the antibiotics produced by this Cephalosporium strain. However, we found that with the first enzyme preparation mentioned above, only partial inactivation was obtained. Table 1 shows the results with such a preparation acting on samples taken at different time intervals from shake-flask cultures containing CSL (840 mg. N/l.) $+2 \%$ glucose, at initial $\mathrm{pH}$ values of $7 \cdot 0$ and $6 \cdot 4$. The results suggest that an acid fermentation favoured the production of an antibiotic insensitive to the enzyme preparation while an alkaline fermentation favoured the production of both types of antibiotic. Later in the fermentation, when alkaline conditions tended in any case to supervene, the distinction was less marked. Similar experiments on other types of fermentation have confirmed this. 
Separation by paper chromatography. Samples of culture fluid were spotted onto $\frac{1}{2} \times 22$ in. strips of Whatman no. 1 filter-paper which had previously been soaked in $20 \%$ potassium phosphate ( $\mathrm{pH} \mathrm{6.15)}$ and dried. They were suspended in a vessel similar to that of Goodall \& Levy (1947), and developed for some hours with amyl acetate saturated with water. After drying at room temperature they were placed on the surface of seeded or unseeded nutrient agar for $1 \mathrm{hr}$., then removed and the agar incubated or streaked with test organisms and then incubated (Pl. 1, figs. 1, 2 and 3).

Table 1. The partial inactivation of Cephalosporium antibiotics by an enzyme preparation containing penicillinase from B. subtilis G.B.S.2

\begin{tabular}{|c|c|c|c|}
\hline \multirow[b]{2}{*}{$\begin{array}{c}\text { Starting } \\
\text { pH }\end{array}$} & \multirow{2}{*}{$\begin{array}{c}\text { Fermentation } \\
\text { time } \\
\text { (hr.) }\end{array}$} & \multicolumn{2}{|c|}{ Titre (arbitrary units) } \\
\hline & & $\begin{array}{c}\text { Before } \\
\text { treatment }\end{array}$ & $\begin{array}{c}\text { After } \\
\text { treatment }\end{array}$ \\
\hline \multirow[t]{3}{*}{$7 \cdot 0$} & 48 & $9 \cdot 2$ & $4 \cdot 7$ \\
\hline & 72 & $17 \cdot 2$ & $11 \cdot 7$ \\
\hline & 96 & $8 \cdot 5$ & $5 \cdot 2$ \\
\hline \multirow[t]{3}{*}{$6 \cdot 4$} & 48 & $4 \cdot 6$ & $\mathbf{3} \cdot \mathbf{1}$ \\
\hline & 72 & 12.9 & 11.2 \\
\hline & 96 & $5 \cdot 7$ & $2 \cdot 1$ \\
\hline
\end{tabular}

When treated in this way and tested against $B$. subtilis 288 , crude active broth gave two inhibition zones having $R_{F}$ values (Consden, Gordon \& Martin, 1944) of 0 and 0.95-1.00; in broth treated with 'penicillinase' only the lower zone $\left(\boldsymbol{R}_{F}=0.95\right)$ occurred. When the broth was first held at $\mathrm{pH} 2$ at room temperature for a few hours, all or nearly all the top zone $\left(\boldsymbol{R}_{p}=0\right)$ disappeared. On the other hand, in broth extracted at $\mathrm{pH} 6$ with an equal volume of amyl acetate only the top antibiotic zone remained in the broth. The amyl acetate extract showed only one zone $\left(\boldsymbol{R}_{F}=0.95\right)$ with some broths, though with others a zone at $R_{F}=0$ also occurred. The material responsible for the latter was not inactivated by 'penicillinase' from $B$. subtilis G.B.S. 2, and differed from the non-extracted top zone antibiotic in other ways. Pl. 1, fig. 4, illustrates chromatograms of material treated in various ways.

Range of antibacterial action. Strips of filter-paper soaked in the solution under test were temporarily applied to a nutrient agar surface which was then cross-streaked with test organisms and incubated. Sometimes portions of chromatographically developed paper strips were cut out and tested in the same way.

The range of antibacterial action of the three types of antibiotic are shown in Table 2. It will be seen from Table 2 that in general the antibiotics soluble in amyl acetate inhibited only the Gram-positive organisms tested, while the acetate-insoluble material inhibited a number of Salmonella spp. and Klebsiella pneumoniae, but not Staph. albus NCTC 7292. Accordingly, the acetateinsoluble antibiotic was called ' $N$ ' and the acetate-soluble antibiotics ' $\mathrm{P}(a)$ ' $\left(R_{F}=0.95\right)$, and ' $\mathrm{P}(b)$ ' $\left(R_{F}=0\right)$. Table 3 shows some properties of the various antibiotic substances so far elucidated. 
Table 2. The inhibition of bacterial growth by antibiotics produced by the Cephalosporium strain

Test organism

B. anthracis (Oxford)

B. megatherium NCTC 2605

B. mesentericus NCTC 6353

B. subtilis (Oxford)

B. subtilis Strain 288 of Distillers Co. Ltd.

Bodenheimer organism (Trussell et al. 1947)

Corynebacterium simplex NCTC 4215

C. xerosis (Oxford)

Bacterium coli (Oxford)

Serratia marcescens NCTC 1377

Klebsiella pneumoniae (Oxford)

Micrococcus lysodeikticus (Oxford)

Micrococcus sp. NCTC 7218

Mycobacterium phlei (Oxford)

Pseudomonas pyocyanea (Oxford)

Salmonella enteritidis (Oxford)

S. typhi (Oxford)

S. typhimurium (Clevedon 6)

Sarcina sp. (Clevedon 8)

Staph. albus NCTC 7292

Staph. albus (Oxford)

Staph. aureus (Clevedon 4)

Staph. aureus Strain G of Distillers Co. Ltd.

Staph, aureus Strain 209 P

Staph. aureus (Oxford)

Strep. lactis NCTC 662

Strep. pyogenes (Oxford)

Pasteurella sp. (Oxford)

\begin{tabular}{|c|c|c|}
\hline \multicolumn{3}{|c|}{ Antibiotic } \\
\hline \multirow{2}{*}{$\begin{array}{c}\text { Insoluble } \\
\text { in amyl } \\
\text { acetate } \\
\mathbf{N}^{*}\end{array}$} & \multicolumn{2}{|c|}{$\begin{array}{c}\text { Soluble in } \\
\text { amyl acetate }\end{array}$} \\
\hline & $\mathbf{P}(a)^{*}$ & $\mathbf{P}(b)^{*}$ \\
\hline $\begin{array}{l}++ \\
++ \\
++ \\
++\end{array}$ & $\begin{array}{c}++ \\
+ \\
++ \\
+\end{array}$ & $\begin{array}{c}++ \\
+ \\
++ \\
+\end{array}$ \\
\hline $\begin{array}{c}++ \\
0\end{array}$ & $\begin{array}{c}++ \\
0\end{array}$ & $\begin{array}{c}++ \\
0\end{array}$ \\
\hline 0? & ++ & ++ \\
\hline $\begin{array}{c}++ \\
0\end{array}$ & $\begin{array}{c}++ \\
0\end{array}$ & $\begin{array}{c}++ \\
0\end{array}$ \\
\hline 0 & 0 & 0 \\
\hline+++ & 0 & 0 \\
\hline++ & + & + \\
\hline++ & +++ & $++t$ \\
\hline $\begin{array}{c}+t+ \\
0\end{array}$ & $\begin{array}{c}++ \\
0\end{array}$ & $\begin{array}{c}+t+ \\
0\end{array}$ \\
\hline++ & 0 & 0 \\
\hline++ & 0 & $\mathbf{0}$ \\
\hline++ & 0 & 0 \\
\hline++ & ++ & ++ \\
\hline 0 & ++ & ++ \\
\hline 0 & + & + \\
\hline++ & +++ & +++ \\
\hline $\begin{array}{c}++ \\
+\end{array}$ & $\begin{array}{c}++ \\
+++\end{array}$ & $\begin{array}{c}++ \\
+++\end{array}$ \\
\hline $\begin{array}{l}++ \\
++\end{array}$ & $\begin{array}{l}+ \\
++\end{array}$ & + \\
\hline++ & $+t$ & ++ \\
\hline$+t+$ & ++ & ++ \\
\hline
\end{tabular}

$0=$ no inhibition; $+=$ some inhibition; $++=$ marked inhibition; $+++=$ very marked inhibition.

* For explanation see text, p. 51.

Table 3. Some properties of the antibiotics produced by the Cephalosporium strain

\section{Property}

Antibiotic to Staph. albus NCTC 7292

Antibiotic to Klebsiella pneumoniae, and many

Gram-negative organisms

Extracted into amyl acetate from acid solution

Inactivated by penicillinase from $B$. subtilis G.B.S.2

Labile in acid solution

Mainly produced in slightly alkaline fermentations

Mainly produced in slightly acid fermentations

\begin{tabular}{|c|c|c|}
\hline \multicolumn{3}{|c|}{ Antibiotic } \\
\hline N* & $\mathbf{P}(a)^{*}$ & $\mathbf{P}(b)^{*}$ \\
\hline - & + & + \\
\hline+ & - & - \\
\hline _- & + & $+t$ \\
\hline+ & - & - \\
\hline+ & - & - \\
\hline+ & - & $?$ \\
\hline - & + & $?$ \\
\hline
\end{tabular}

* These symbols have same significance as in Table 2 ; see p. 51 .

$\dagger$ But possibly strongly adsorbed to paper fibres. 
Test organisms for differential assay. Staph. albus NCTC 7292 was strongly inhibited by $\mathrm{P}(a)$ and $\mathrm{P}(b)$, but not at all by $\mathrm{N}$, while $K$. pneumoniae was strongly inhibited by $\mathrm{N}$ but not at all by either $\mathrm{P}(a)$ or $\mathbf{P}(b)$. These organisms were therefore tested for differential assay and appeared to be entirely satisfactory.

\section{CULTIVATION OF THE CEPHALOSPORIUM STRAIN AND THE PRODUCTION OF THE 'P' ANTIBIOTICS}

Culture maintenance and preparation of inocula

A 15-day culture was suspended in ascorbic acid freeze-drying medium (Naylor \& Smith, 1946) in double constriction ampoules, frozen at $-78^{\circ}$, and dried at low pressure. The ampoules were afterwards sealed at atmospheric pressure and stored at $4^{\circ}$. The percentage survival of the dried material has so far (18 months) proved satisfactory. The mere process of drying was found to have no detectable effect on subsequent antibiotic titre. An ampoule was opened each month and slants sown from it were used for inoculating weekly stock cultures.

Spore inoculum. 'Bowpanel flats' (20 oz.), each containing $110 \mathrm{ml}$. of the surface culture medium described by LePage \& Campbell (1946), with the addition of $2 \%$ agar, were sown with $1.5 \mathrm{ml}$. of a spore suspension, incubated for 14 days at $24^{\circ}$, and stored for not less than 1 day or more than 6 days at $4^{\circ}$. Glass beads in $40 \mathrm{ml}$. distilled water were used to wash off spores as required, a thick uniform suspension being obtained.

Inoculum by submerged culture. When large quantities of inoculum were required, submerged cultures were used. They were prepared in 101 . Pyrex aspirators agitated by a paddle type stirrer running at 150 r.p.m. and aerated by a horizontal perforated glass tube entering through the lower outlet of the aspirator. A second tube from this outlet was attached to a sampling device. Each aspirator was charged with $8 \mathrm{l}$. of CSL + glucose medium (see below), and autoclaved $1 \mathrm{hr}$. at $120^{\circ}$. Spore suspension $(160 \mathrm{ml}$.) was added as inoculum, and the aspirators were aerated (with stirring) at $24^{\circ}$ for $72 \mathrm{hr}$. After testing for contamination, the sampling device was replaced by a separately sterilized apparatus consisting of a calibrated measuring device with a hooded pipette, from which uniform volumes of inoculum could be dispensed.

Size of inoculum. In most fermentations the inoculum, of spores or submerged growth, was $2 \%(\mathrm{v} / \mathrm{v})$ of the medium to be inoculated.

\section{Fermentation vessels}

Shake flasks. Narrow-mouthed $250 \mathrm{ml}$. Erlenmeyer flasks containing $50 \mathrm{ml}$. of medium were agitated on a horizontal shaker giving 84 oscillations/min.; length of throw $7 \cdot 5 \mathrm{~cm}$.

Stirred aerated flasks. The constructional details and use of these 5 l. bolthead flasks is described by Kelly, Miller \& Hale (1952). The flasks contained 4. 1 . of medium, could be aerated at $61 . / \mathrm{min}$., and the stirrer (fitted with short lengths of stainless steel chain if desired) could run at 900 r.p.m. Speed of 
stirring and aeration rate could be varied over a wide range. The flasks were arranged in groups of $\mathbf{1 6}$ to facilitate statistical design and analysis of the experiments.

Stirred aerated stainless steel fermenter. A 100 gal. fermenter modified from a stainless steel mixing vessel was employed; stirring was at 400 r.p.m. and aeration at 20-21 cu.ft./min.

Antifoam agents. It was necessary to add antifoam agents to the $5 \mathrm{l}$. and 100 gal. fermenters. A mixture of tri-amyl citrate (400 p.p.m.), and Dow Corning Silicone 'A' (160 p.p.m.) was usually used to control foaming in the $5 \mathrm{l}$. vessels; lower concentrations could be used in the 100 gal. fermenter. Certain batches of CSL caused more foaming than others and more antifoam mixture had to be used. No decrease of yield of antibiotics was found when larger concentrations of antifoam were added in controlled experiments.

\section{Assay}

The method of assay of Cephalosporin $\mathbf{P}$ was similar to that developed for streptomycin by Brownlee et al. (1948). At first $B$. subtilis 288 was used as test organism, but was replaced by Staph. albus NCTC 7292 when this was shown to be specially inhibited by the $\mathbf{P}$ antibiotics.

The medium consisted of : Evans's peptone, $1 \%$; sodium chloride, $0.35 \%$; Armour's meat extract, $0.3 \%$; Yeastrel, $0.15 \%$; agar, $2 \%$. The $\mathrm{pH}$ was adjusted to $7 \cdot 4$ and the medium autoclaved, filtered, distributed and reautoclaved at $15 \mathrm{lb}$./sq.in. for $20 \mathrm{~min}$. Volumes of $110 \mathrm{ml}$., held at $45^{\circ}$, were inoculated with $1 \mathrm{ml}$. of a suspension of the test organism, then poured into the special plates. The suspension was prepared from $48 \mathrm{hr}$. nutrient agar ( $\mathrm{pH} 7$ ) slants of the Staph. albus, and was diluted to match opacity four of the Brown's opacity tubes (Burroughs Wellcome and Co. Ltd).

Preparation of samples for assay. The samples of culture fluid were centrifuged and diluted in $0.2 \mathrm{M}$ phosphate buffer $(\mathrm{pH} 7 \cdot 0$ ) to give two solutions at $c .4$ and $2 \mathrm{u} . / \mathrm{ml}$. Standard solutions were also prepared to contain exactly 4 and $2 \mathrm{u} . / \mathrm{ml}$. Samples of cephalosporin $\mathbf{P}$ in amyl or butyl acetate were prepared by evaporating a known volume to dryness in a current of air; the residue was dissolved in $\mathbf{0 . 1} \mathrm{ml}$. acetone then made up to volume in $\mathrm{pH} 7$ phosphate buffer.

Procedure. This was as described by Brownlee et al. (1948), the plates being incubated for about $16 \mathrm{hr}$. at $32^{\circ}$, and the zones measured on an enlarger. The method of calculation was that described by Brownlee, Lorraine \& Stevens (1949).

Unit of activity, standard, etc. As soon as a solid preparation believed to be substantially pure $\mathbf{P}$ antibiotic(s) became available, the unit was redefined as the activity in $10 \mu \mathrm{g}$. of this solid preparation. This unit was approximately equivalent to that originally adopted.

\section{RESULTS}

Sporulation medium. Cultures on a wide variety of stock media were compared, and from the best of them spore suspensions were prepared and counted in a haemocytometer. LePage \& Campbell (1946) medium was found 
to give an appreciably higher spore count, especially from older slants, and was therefore adopted as a suitable sporulation medium. A very good growth was obtained in 3 days at $24^{\circ}$, and by 14 days complete sporulation had taken place, indicated by the somewhat translucent appearance of the growth. Slants washed off earlier than 14 days and without at least 1 day's storage at $4^{\circ}$, were extremely difficult to suspend; the resulting suspensions then contained large pieces of felt and formed very poor inocula.

Effect of age of sporing culture on antibiotic production. Spore suspensions from slants of 9 days and $3,4,6,8,9$ and 12 weeks were compared for antibiotic production in shake flasks. The 3- and 4-week slants appeared to give the best titres. When slants between 10 and 28 days old were carefully compared, the optimum yield was from slants 14-18 days old, though those up to 28 days old were almost as good.

The effect of repeated subculture on yield of antibiotic. With frequently subcultured strains the antibacterial activity developed more slowly than with seldom transferred strains, although the same titre was reached in each by $72 \mathrm{hr}$. The number of transfers was therefore kept to a minimum.

\section{Investigations on different inocula}

Spore inoculum. Various volumes of spore inoculum, prepared as above, were tested in shake culture flasks. With the inoculum forming 2,3 or $4 \%(v / v)$ of the volume of medium the same optimum titre was reached. With smaller volumes of inoculum activity appeared later and often did not reach the same level.

Submerged inoculum. Whether in shake flasks or in $10 \mathrm{l}$. aspirators, 72-96 hr. appeared to be the optimum incubation time for submerged inocula preparation. The inoculum was tested in both shake flasks and in 5 l. stirred aerated flasks; the results from the latter vessels are shown in Table 4.

Table 4. Influence of age of submerged culture inoculum on Cephalosporin $\boldsymbol{P}$ production

(The inoculum was grown in $10 \mathrm{l}$ stirred aerated aspirators for the times shown.)

\begin{tabular}{|c|c|c|c|c|}
\hline \multirow{3}{*}{$\begin{array}{c}\text { Period of } \\
\text { fermentation } \\
\text { (hr.) }\end{array}$} & \multicolumn{4}{|c|}{ Age of inoculum (hr.) } \\
\hline & $\mathbf{2 4}$ & 48 & 72 & 96 \\
\hline & \multicolumn{4}{|c|}{ Units of Cephalosporin $\mathrm{P} / \mathrm{ml}$. (av. of four fermentations) } \\
\hline $\mathbf{2 3}$ & . & $1 \cdot 1$ & $\mathbf{2 \cdot 2}$ & $\mathbf{2 \cdot 4}$ \\
\hline $44 \cdot 5$ & 0.95 & $4 \cdot 9$ & $10 \cdot 3$ & $10 \cdot 1$ \\
\hline 49 & 1.8 & $5 \cdot 9$ & $11 \cdot 3$ & $9 \cdot 8$ \\
\hline
\end{tabular}

The optimum size of submerged inoculum was investigated in shake flasks and in $5 \mathrm{l}$. stirred aerated flasks. In both types of vessel maximum production was obtained with a $2 \%(v / v)$ inoculum, though with $4 \%(v / v)$ the same titre was reached more rapidly. With less than $2 \%(\mathrm{v} / \mathrm{v})$ inoculum, rate of production and ultimate yield were smaller. Table 5 shows the results of an experiment with the 5 l. flasks. 
Table 5. Influence of size of inoculum on the production of Cephalosporin $\boldsymbol{P}$

\begin{tabular}{|c|c|c|c|c|}
\hline \multirow{2}{*}{$\begin{array}{c}\text { Period of } \\
\text { fermentation } \\
\text { (hr.) }\end{array}$} & \multicolumn{4}{|c|}{ Size of inoculum, as $\%$ of total volume } \\
\hline & $\begin{array}{c}0.5 \% \\
\text { Units }\end{array}$ & $\begin{array}{c}1 \% \\
\text { sporin } F\end{array}$ & $\begin{array}{l}2 \% \\
\text { eight }\end{array}$ & $\begin{array}{l}4 \% \\
\text { ns) }\end{array}$ \\
\hline 24 & 0.7 & $1 \cdot 6$ & $2 \cdot 9$ & $5 \cdot 2$ \\
\hline 28 & $1 \cdot 6$ & $3 \cdot 2$ & $4 \cdot 9$ & $8 \cdot 2$ \\
\hline 47 & $9 \cdot 7$ & $10 \cdot 5$ & $11 \cdot 2$ & $13 \cdot 0$ \\
\hline 50 & $12 \cdot 1$ & $12 \cdot 0$ & $13 \cdot 1$ & $13 \cdot 0$ \\
\hline
\end{tabular}

Comparison of spore and submerged inoculum. Table 6 shows the titres obtained in shake flask cultures inoculated with $2 \%(\mathrm{v} / \mathrm{v})$ of $(a)$ spore inoculum, or $(b) 72 \mathrm{hr}$. submerged inoculum. The true peak titres of the latter may well have been missed, but no significant difference in level is suggested.

Table 6. Comparison of spore and submerged culture inocula

\begin{tabular}{|c|c|c|c|}
\hline & \multicolumn{3}{|c|}{ Period of fermentation (hr.) } \\
\hline & \multirow{2}{*}{\multicolumn{3}{|c|}{$\begin{array}{ccc}40 & 64 & 88 \\
\text { Units Cephalosporin } & \text { P/ml. (av. of four fermentations) }\end{array}$}} \\
\hline & & & \\
\hline $\begin{array}{l}2 \%(v / v) \text { spore suspension } \\
2 \%(v / v) \text { submerged culture }\end{array}$ & $\begin{array}{l}4 \cdot 2 \\
6 \cdot 4\end{array}$ & $\begin{array}{l}7 \cdot 6 \\
9 \cdot 8\end{array}$ & $\begin{array}{r}11 \cdot 0 \\
9 \cdot 1\end{array}$ \\
\hline
\end{tabular}

\section{Composition of medium and fermentation conditions}

Corn steep liquor + glucose medium. A number of experiments were set up in stirred aerated $5 \mathrm{l}$. flasks and aspirator bottles with various concentrations of CSL $(1-5 \%, v / v)$, and glucose $(1-4 \%, w / v)$. These all indicated as optimum $2.5 \%(\mathrm{v} / \mathrm{v}) \mathrm{CSL}+2 \%(\mathrm{w} / \mathrm{v})$ glucose. Owing to variations in Kjeldahl nitrogen between different batches of CSL, in later work the amount of CSL taken was that required to provide $840 \mathrm{mg}$. N/l., rather than $2 \cdot 5 \%(\mathrm{v} / \mathrm{v})$.

Inorganic additions to basal medium. Various concentrations of sodium, potassium, iron, magnesium, chloride, sulphate and phosphate were added as individual salts and in combinations. No increase in $\mathbf{P}$ antibiotic was obtained, although some salts depressed both growth and titre.

Other media. None of the other media tested gave higher yields of the $P$ antibiotics than the above basal medium. In view of the low cost and simplicity of the latter more exhaustive investigations were not made.

Temperature of fermentation. The temperature adopted for all fermentations was $24^{\circ}$. At $28^{\circ}$ no change in titre was observed, so that the slight rise of temperature in the 5 l. flasks which began after $20 \mathrm{hr}$. and reached its maximum of $3^{\circ}$ after $50 \mathrm{hr}$. was probably of no significance.

Aeration and stirring. The air demand of this Cephalosporium strain seems to be far higher than that of other fungi grown under similar conditions, and high stirrmg and aeration rates were required. This is illustrated in Table 7, and by the fact that full antibiotic production took longer in shake flasks than in well aerated and stirred flasks. 
Hydrogen-ion concentration. The $\mathrm{pH}$ value of the medium had a marked effect on the nature of the antibiotics formed. For the production of $\mathbf{P}$ antibiotics, an initial $\mathrm{pH}$ of $\mathbf{6 \cdot 3}$ (after sterilization) was adopted as standard.

Table 7. Influence of stirring and aeration on Cephalosporin $\boldsymbol{P}$ production

\begin{tabular}{|c|c|c|c|c|c|c|}
\hline \multirow{3}{*}{$\begin{array}{l}\text { Aeration } \\
\text { rate } \\
(1 . / \mathrm{min} .)\end{array}$} & \multirow{3}{*}{$\begin{array}{c}\text { Stirring } \\
\text { rate } \\
\text { (r.p.m.) }\end{array}$} & \multicolumn{5}{|c|}{ Period of fermentation (hr.) } \\
\hline & & 24 & & 30 & 48 & 50 \\
\hline & & \multicolumn{5}{|c|}{ Units Cephalosporin $\mathbf{P} / \mathrm{ml} .^{*}$} \\
\hline 12 & 900 & $2 \cdot 6$ & $3 \cdot 4$ & 6.8 & 13.0 & 14.0 \\
\hline 6 & 900 & $\mathbf{2 \cdot 4}$ & $4 \cdot 8$ & $8 \cdot 5$ & $13 \cdot 0$ & $13 \cdot 0$ \\
\hline 12 & 600 & $1 \cdot 3$ & $1 \cdot 6$ & $2 \cdot 9$ & $7 \cdot 1$ & $7 \cdot 7$ \\
\hline 6 & 600 & 0.9 & $1 \cdot 5$ & $2 \cdot 1$ & $4 \cdot 6$ & $4 \cdot 8$ \\
\hline
\end{tabular}

* Av. of fifteen fermentations obtained by bulking samples.

Fermentation in the 70 gal. fermenter

With the standard medium the optimum period of fermentation at $24^{\circ}$ was 47-50 hr., when the titre was $9-13 \mathrm{u} . / \mathrm{ml}$. Fig. 1 shows the course of antibiotic production and some chemical changes in the medium. It will be seen that

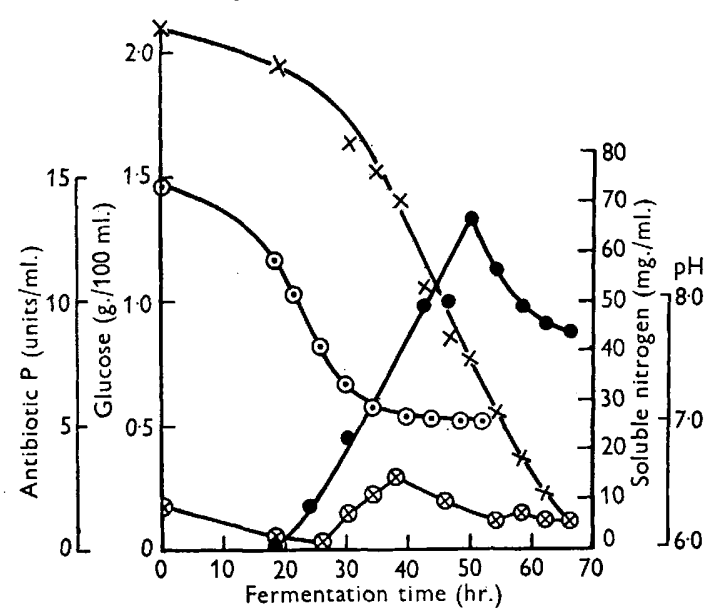

Text-fig. 1. Changes occurring during a 70 gal. Cephalosporin $P$ fermentation.

Cephalosporin P; $\times-\times$, glucose; $\odot-\odot$, soluble nitrogen; $\otimes-\longrightarrow \otimes$, pH. In this particular fermentation, the initial glucose concentration was increased to $3 \%$ of the impure monohydrate.

the titre falls off rapidly after the peak has been passed. After growth the 70 gal. of brew were adjusted to $\mathrm{pH} \mathrm{5.0}$ and the mycelium removed by filtration through a cloth bag-filter. The filtrate was extracted with butyl acetate at $\mathrm{pH} \mathrm{6-6.5}$ by the methods described by Burton \& Abraham (1951), practically $100 \%$ of the $\mathbf{P}$ antibiotics being so extracted.

Our thanks are due to Sir Howard Florey for suggesting this work and for his interest and encouragement. 


\section{REFERENCES}

Brotzu, G. (1948). Ricerche su di un nuovo antibiotico. Labori dell'Istituto d'Igiene di Cagliari.

Brownlee, K. A., Delves, C. S., Dorman, M., Green, C. A., Grenfell, F., Johnson, J. D. S. \& SMrth, N. (1948). The biological assay of streptomycin by a modified cylinder plate method. J. gen. Microbiol. 2, 40.

Brownlee, K. A., Lorraine, P. K. \& Stephens, J. (1949). The biological assay of penicillin by a modified plate method. J. gen. Microbiol. 3, 347.

Burton, H. S. \& Abraham, E. P. (1952). Isolation of antibiotics from a species of cephalosporium. Cephalosporins P1, P2, P3, P4 and P5. Biochem. J. (in the Press).

Consden, R., Gordon, A. H. \& Martin, A. J. P. (1944). Qualitative analysis of proteins: a partition chromatographic method using paper. Biochem. J. 38, 224.

DuthIE, E. S. (1944). The production of penicillinase by organisms of the subtilis group. Brit. J. exp. Path. 25, 96.

Gill-Carey, D. (1950). Surface and submerged growth of Coprinus quadrifidus. Brit. J. exp. Path. 31, 30.

Goodall, R. R. \& LEvi, A. A. (1947). A microchromatographic method for the detection and approximate determination of the different penicillins in a mixture. Analyst, 72, 277.

Heatrey, N. G. (1944). A method for the assay of penicillin. Biochem. J. 38, 61.

Heatley, N. G. \& Florey, H. W. (1946). An antibiotic from Bacterium coli. Brit. J. exp. Path. 27, 378.

Kelly, B. K., Mrller, G. A. \& Hale, C. W. (1952). The development of culture media for large-scale production of micrococcin. J. gen. Microbiol. 6, 41 .

LePage, G. A. \& Campbell, E. (1946). Preparation of streptomycin. J. biol. Chem. $162,163$.

NAYLoR, H. B. \& SMTTH, P. A. (1946). Factors affecting the viability of Serratia marcescens during dehydration and storage. J. Bact. 52, 565.

Ritchie, A. C., Smith, N. \& Florey, H. W. (1951). Some biological properties of cephalosporin P1. Brit. J. pharmacol. 6, 430.

Trussell, P. C., Fulton, C. O. \& Grant, G. A. (1947). Two antibiotics produced by a Streptomyces. J. Bact. 53, 769.

\section{EXPLANATION OF PLATE}

Fig. 1. Examination of antibioties produced by a Cephalosporium sp., by bacterial spectra on zones from chromatographically developed filter strips placed on agar seeded with B. subtilis 288. Top $\mathbf{N}$ zones and lower $\mathrm{P}$ zones were streaked with various test organisms. The order of streaking is varied on the two strips so that each organism may cross each zone once. Test organisms: (1) K. pneumoniae (Oxford); (2) Staph. aureus G; (3) Staph. albus NCTC 7292.

Fig. 2. Zones from paper strip on agar plate seeded with Klebsiella pneumoniae (cf. Fig. 1). Showing top zone, Cephalosporin N. Presence of lower zone (Cephalosporin $\mathbf{P}$ antibiotics) demonstrated by inhibition of certain streaks. Test organisms: (1) Staph. aureus (Oxford); (2) S. typhimurium (Clevedon 6); (3) Staph. albus NCTC 7292; (4) B. subtilis (Oxford).

Fig. 3. Zones from paper strip on agar plate seeded with Staph. albus NCTC 7292 (cf. Fig. 1). Showing lower zone, Cephalosporin P. Presence of top zone (Cephalosporin N) demonstrated by inhibition of streaks. Test organisms : (1) K. pneumoniae; (2) S. typhimurium; (3) Staph. aureus. 
Journal of General Microbiology, Vol. 6, No. $1 \& 2$

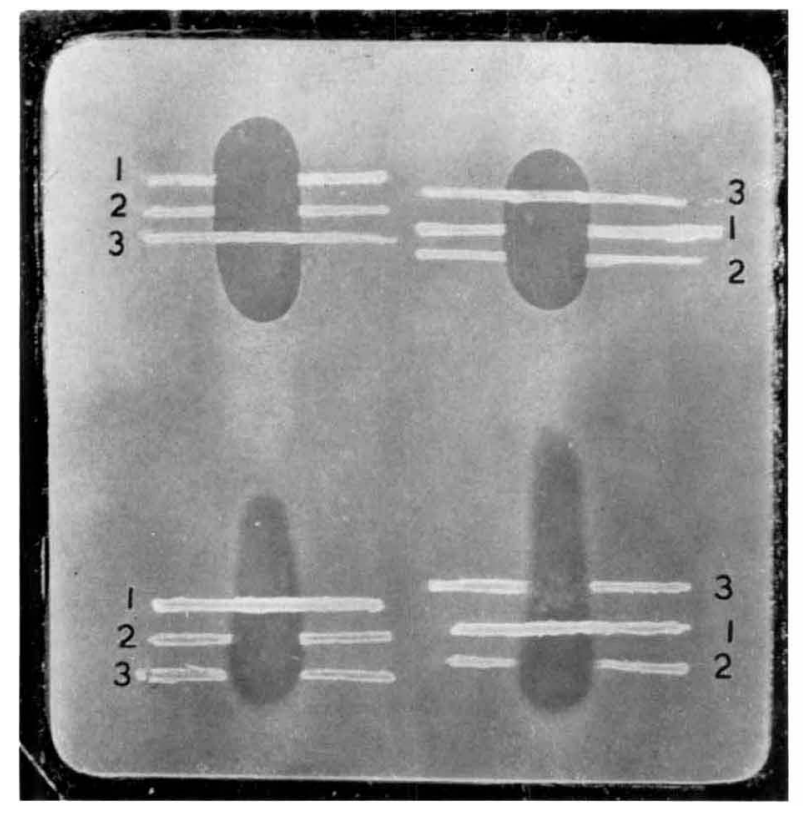

Fig. 1

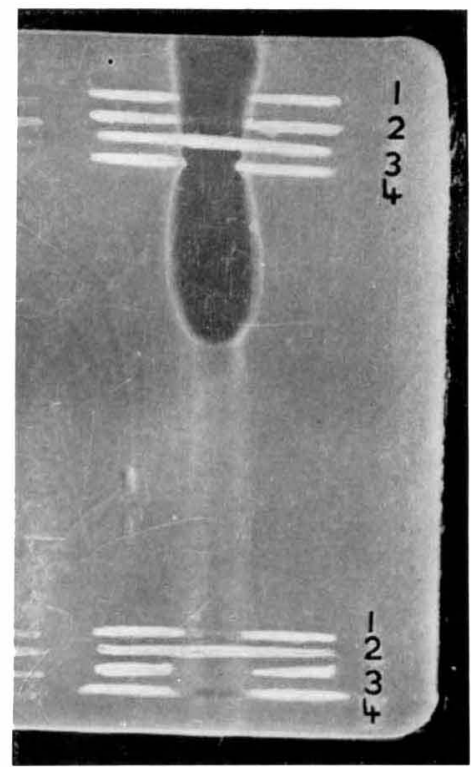

Fig. 2

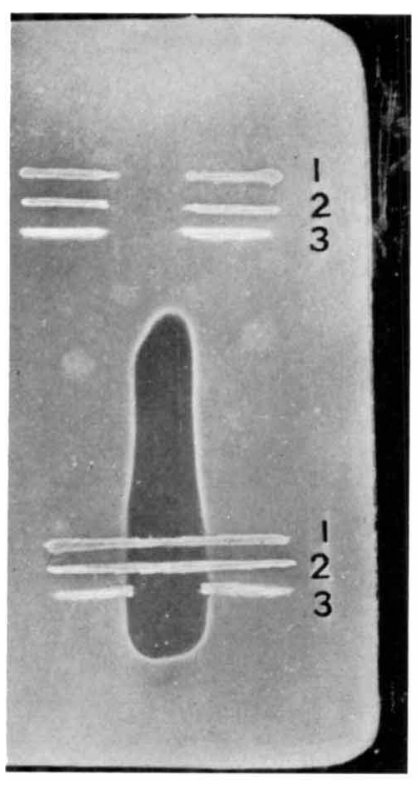

Fig. 3

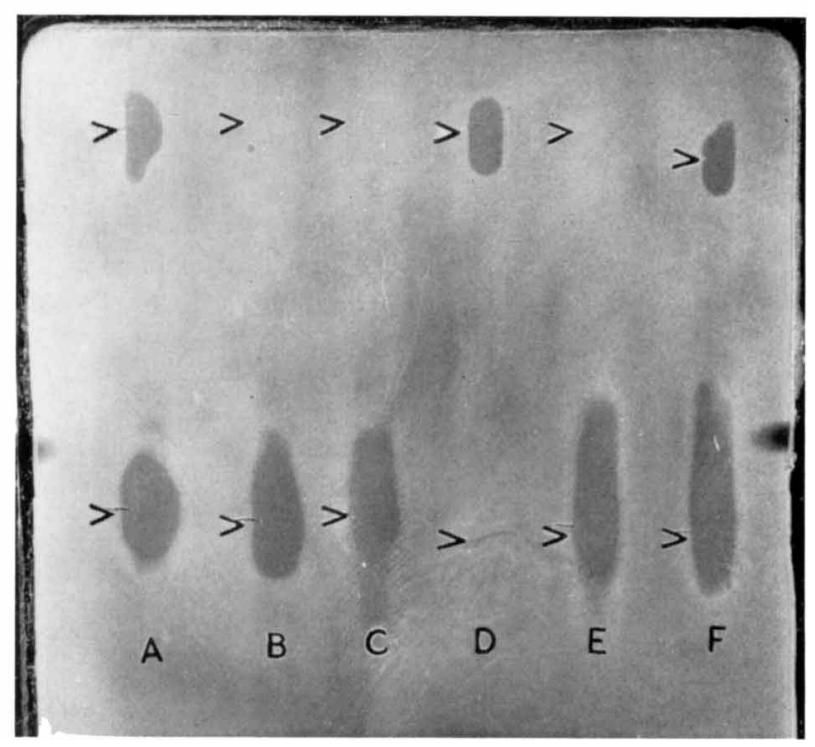

Fig. 4

Kathleen Crawfond et al.-Cephalosporium antibiotics. Plate 1 


\section{Cephalosporium antibiotics}

Fig. 4. Zones from paper strips developed with amyl acetate, on agar seeded with $B$. subtilis 288. Upper arrow indicates point of application; lower arrow indicates solvent front. $A$, culture filtrate showing both zones; $B$, culture filtrate after treatment with 'penicillinase' from $B$. subtilis G.B.S. 2 ; $C$, culture filtrate after storage for 3 hr. at pH 2 ; $D$, aqueous residue after extraction of culture filtrate with amyl acetate; $E$, amyl acetate extract from $D ; F$, an amyl acetate extract showing two $\mathrm{P}$ zones.

(Received 25 May 1951) 